* Graduado e mestre em Direito pela Universidade de Marília UNIMAR. Foi bolsista PROSUPCAPES entre 2017 e 2019. Advogado.

E-mail: joaopceren@gmail.com

** Mestrado em Direito Constitucional pela Universidade de Fortaleza com período sanduíche na Universidade Federal de Santa Catarina - UFSC e doutorado em Direito pela UFSC, tendo realizado o doutorado sanduíche na Universidade de Zaragoza (Espanha) com bolsa do PDSE da CAPES e período de investigação na Universidade Federal da Paraíba - UFPB com bolsa do PROCAD da CAPES. Atualmente é professor permanente do Programa de Pós-Graduação em Direito da UNIMAR e diretor de relações institucionais do CONPEDI. E-mail: vmcarmo86@gmail.com

\section{Crítica ho Compliance na Lei Brasileira de ANTICORRUPÇÃo}

\author{
COMPLIANCE's CRITIC In BRAZILIAN ANTI-CORRUPTION \\ LAW
}

\author{
João Pedro Ceren* \\ Valter Moura do Carmo**
}

Como citar: CEREN, João Pedro; CARMO, Valter Moura do. Crítica ao compliance na lei brasileira de anticorrupção. Revista do Direito Público, Londrina, v. 14, n. 3, p. 87-109, dez. 2019. DOI: $10.5433 / 24157-108104-1.2019 v 14 n 3 p$. 87. ISSN: $1980-$ $511 \mathrm{X}$

Resumo: Sob o influxo de combater a corrupção e responsabilizar também as pessoas jurídicas de forma objetiva, surgiu a lei $\mathrm{n}^{\mathrm{o}}$ 12.846 de 2013 conhecida como lei anticorrupção, trazendo alguns institutos salutares para os mais otimistas, e institutos repetidos para os mais céticos, uma vez que a lei traz disposições já existentes em solo nacional como na lei de improbidade administrativa e na lei de licitações, a título de exemplo. Fato é que o Brasil, com a promulgação da lei em apreço, adequouse à realidade internacional, trazendo mais um dispositivo para vedar atos maculados oriundos não só de agentes públicos como também de pessoas jurídicas, alinhando-se a ideias de compliance. Todavia, o compliance previsto na lei anticorrupção é algo benéfico, ou este é um discurso repetido sem razão? O artigo trará críticas ao instituto do compliance, por meio da interpretação e da comparação com a realidade internacional para chegarmos ao resultado que é objeto deste artigo, desvendar se o instituto é realmente eficaz do jeito que foi proposto na lei anticorrupção ou se a utilização pode tornar-se apenas artífice para aqueles que querem se utilizar de uma nova manobra para evitar penalidades. Para tal, será utilizado o método dedutivo.

Palavras-chave: Compliance. Corrupção. Estatais; Direito administrativo.

Abstract: Law n. 12,846 of 2013, also known as the Brazilian Anti-corruption Law, was created with the aim of combating 
corruption as well as holding legal entities responsible for their actions. For the optimistic few, it created salutary institutes. However, for those who are a bit more skeptical, it is easy to see that it doesn't innovate in its institutes, as it copies perfectly already known provisions existing in the Brazilian Legal System, such as the law of administrative impropriety and the law governing public contracts. It happens that, with the enactment of this law, Brazil conformed to the international standard, creating legal provisions to regulate and punish maculate acts originating not only from civil servants but also from legal entities - thusly, aligning itself with modern compliance ideas. Yet this paper questions, if the compliance prescribed in the anti-corruption law is beneficial, or if it is an empty repeated promise? From this question, this study offers a much needed criticism of the institute of compliance, utilizing a moray of interpretations and comparisons with foreign and international law as a means for reaching this manuscript's objective, ie, to find out if compliance is an effective instrument for combating corruption as proposed in the anti-corruption law or if it can become an artifice for those who want to use it in order to avoid penalties. For this reason, this paper uses the deductive method.

Keywords: Compliance. Corruption. State. Administrative law. 


\section{INTRODUÇÃO}

A corrupção não é um mal que assola apenas o Brasil, suas consequências ultrapassam fronteiras culturais, linguísticas e econômicas. O problema atualmente é visto e combatido coletivamente, visto que as consequências desse mal atingem proporções mundiais. Frente ao problema, o Brasil vem adotando formas de mitigar a corrupção por meio de tratados internacionais, como a Convenção Interamericana contra a Corrupção, a Convenção sobre o Combate da Corrupção de Funcionários Públicos Estrangeiros em Transações Comerciais Internacionais da Organização para a Cooperação e Desenvolvimento Econômico (OCDE), dentre outras medidas de cunho internacional e nacional.

Fruto da necessidade de combater a corrupção no plano interno, surgiu a lei anticorrupção (12.846 de 2013), inspirada por diplomas internacionais como o Bribery Act e o Foreign Corrupt Practices Act. Embora seja recente, trouxe temas muito relevantes para o combate à corrupção. Para citá-los, apenas a título de exemplo: a responsabilidade objetiva da pessoa jurídica, o Cadastro Nacional de Empresas Punidas, o acordo de leniência, e a criação de uma cultura de compliance, visto que a legislação traz um incentivo para tal. Apesar das inovações benéficas trazidas pela lei, o escopo do presente artigo recairá sobre um tópico negligenciado até então, a efetividade do compliance previsto na lei anticorrupção.

O foco crítico da pesquisa mostra-se relevante em razão de existirem algumas brechas encontradas no dispositivo que incentiva o uso do compliance pelas pessoas jurídicas, o que pode beneficiar inclusive as que não o praticam de forma adequada, utilizando-o apenas como artífice jurídico para outras finalidades.

A lei incentiva a cultura do compliance, pois se a pessoa jurídica mantém uma postura ética cumprindo os requisitos legais, pode eventualmente reduzir a pena pecuniária prevista na lei anticorrupção, caso venha cometer algum delito previsto na própria lei. Porém, o legislador, ao possibilitar a concessão do benefício, não levou em conta o critério da temporalidade, ou seja, qual é o marco que encaixará as empresas que mantém um comportamento ético, das que não seguem tal raciocínio, mas aderem apenas para benefício próprio e malefício da coletividade, e do próprio instituto do compliance.

As análises feitas no artigo científico recairão na obrigatoriedade ou não das práticas de compliance por todas as pessoas jurídicas, e se o compliance previsto na lei anticorrupção é benéfico levando-se em conta o critério da temporalidade, comparando o instituto nacional com a realidade dos diplomas Bribery Act e da Foreign Corrupt Practices Act. Para tal, será utilizado o método dedutivo de pesquisa, bem como diversos textos de autores nacionais e estrangeiros para a fundamentação dos argumentos aqui tecidos.

O artigo, longe de esgotar os questionamentos que envolvem o tema, tenta trazer respostas para o assunto sob um ponto de vista crítico e sóbrio, abordando, nas linhas subsequentes, tópicos conexos para um melhor entendimento da matéria. 


\section{CORRUPÇÃO}

Os Estados-nação, em razão de sua tarefa de gerir, criar, modificar ou extinguir benefícios e ônus, têm uma importante missão de equilibrá-los para que não se criem vantagens desproporcionais para certos indivíduos (incluindo as pessoas jurídicas) e ruína para outros.

Quando um indivíduo quer prerrogativa de tratamento, vantagem econômica (que pode se desdobrar em contratos vantajosos, cláusulas benéficas, prioridade processual, ou mesmo sentença favorável) dentre tantas modalidades de atos, conforme a imaginação humana, não a merecendo, ou seja, quando não há motivos legais para tal, e quando os há abusa de seu direito prejudicando os demais ainda que indiretamente, oferecendo pagamento em dinheiro ou em outra espécie com a finalidade de permutar o benefício desejado, manifesta-se a corrupção. "A própria corrupção pode ser considerada como uma distorção da premissa que serve como substrato da dicotomia público-privado. Esta dicotomia, concebida para atingir o bem comum, é corrompida de maneiras e intensidades diferentes no processo corruptivo." (BLANCHET; AZOIA, 2017, p.164).

Podemos considerar a corrupção como um indício, um prognóstico de que existem sérias imperfeições na relação entre Estado e indivíduos (ACKERMAN, 1999), exemplificando da seguinte forma: em um Estado no qual a burocracia mostra-se como verdadeiro óbice para a realização de uma obra, elevando seus custos, tornando sua execução um transtorno, o indivíduo (ou pessoa jurídica) a quem incumbe a tarefa, pode avaliar os custos de pagar ilicitamente um agente público para antecipar determinada documentação. Percebe-se que onde há ineficiência e dificuldade de relação entre Estado e particular, existe solo propício para atos eivados de corrupção.

A corrupção gera a desigualdade e esta se torna seu principal combustível, ambas ligadas de forma umbilical. Não é errôneo afirmar que a corrupção e a democracia formam uma união onde não há harmonia, já que a natureza daquela corrompe verdadeiramente a essência desta (YAZIGI, 1999). Mais que isso, como efeito indireto da crescente desigualdade que a corrupção fomenta, movimentos populistas são cada vez mais atrativos aos olhos de uma população que não vê resultado, vê a gangrena no corpo social doente, mas não vê o emplastro, enxergam-se apenas promessas vazias e abstratas de combater a corrupção sem medidas práticas.

O fenômeno analisado, qual seja, a corrupção, não é novo, embora venha ganhando espaço nos noticiários nos últimos tempos, "Pelo contrário, a corrupção acompanha o homem desde o início da civilização, de modo que, inclusive, tem sido considerada por renomados filósofos como resultado de uma má natureza própria do ser humano.” (PORTO; WERLE, 2015, p. 139).

Álvaro Filipe Oxley da Rocha e Maiquel Ângelo Dezordi Wermuth (2008, p. 155) trazem um nexo entre a corrupção na seara política e a cordialidade:

A corrupção na política pode ser tomada como a principal consequência da relação simbiótica entre o patrimonialismo e o clientelismo. A forma privatística de gestão do público que marca historicamente o campo político brasileiro baseia-se precipuamente nas relações pessoais de cordialidade estabelecidas entre aqueles que detêm em suas mãos o monopólio do poder e nas relações de 
troca de favores entre estes e a população alçada à condição de "clientes" [...] A partir das relações de cordialidade, portanto, utilizam-se as instituições do Estado para que dívidas de cunho pessoal ou político sejam constantemente criadas e sanadas, em uma espécie de círculo vicioso. Com isso, aquilo que aos olhos do homem civil constitui "corrupção", é visto pelo homem cordial como uma "prova de amizade".

Podemos associar a desigualdade, a corrupção, e os movimentos populistas autocráticos com informações oriundas do Índice de Percepção de Corrupção (ou em inglês Corruption percpetion index - CPI) elaborada pela Transparência Internacional ${ }^{1}$. Para entendermos a colocação dos países no ranking, primeiramente é necessário entendermos a pontuação para avaliar a corrupção: quanto menor o número em uma escala de 0 a 100, mais práticas corruptivas existem naquele país, a contrário sensu, quanto maior o número, mais práticas honestas e maior integridade é encontrada naquele solo. Países que recebem pontuação na escala menor que 50, a corrupção é altamente elevada e perceptível hodiernamente (TRANSPARENCY INTERNATIONAL, 2017). Ressaltamos que a avaliação do Índice de corrupção elaborada em 2016 demonstra que mais de 2/3 dos 176 países e territórios estão abaixo da escala de 50 pontos (TRANSPARENCY INTERNATIONAL 2017), situação que ainda ocorre no ano de 2017 (TRANSPARENCY INTERNATIONAL, 2018), ou seja, a corrupção globalmente não diminuiu. As três últimas colocações são ocupadas respectivamente por Somália, que no ano de 2016 ostentou 10 pontos e no ano de 2017 caiu para 9 pontos, país que vive em estado de guerra desde 1991 quando o ditador Mohamed Siad Barre foi deposto, o que propiciou ao país tornar-se alvo de radicais islâmicos; Sudão do Sul, com 11 pontos em 2016, porém com um aumento de um ponto no ano de 2017, nação de maioria cristã que surgiu após anos de guerra civil com o Sudão do Norte de maioria islâmica, e a Síria marcada por uma profunda guerra civil que ainda se estende, conflito marcado pela opressão do ditador Bashar al Assad e os opositores de seu governo, com pontuação de 14 pontos no ano de 2016, e 17 pontos no ano de 2017.

Quanto ao Brasil, no ano de 2016, este ocupava a $79^{\circ}$ posição na escala de corrupção com 40 pontos, situação que reflete internacionalmente e nacionalmente como o Brasil anda. Porém, em 2017, a situação do país se agravou, pois se encontra na $96^{\circ}$ posição com 37 pontos. Embora o povo brasileiro tenha adquirido uma percepção maior da corrupção como verdadeiro fenômeno

1 Para ser calculado o Índice de Percepção da Corrupção são necessários alguns passos para que seja feito tal empreitada. Com o fito de tornar a metodologia mais palatável ao leitor segue uma explicação mais didática com um enfoque menos técnico: 1- o primeiro passo é a coleta de dados que engloba: a) quantificar a percepção da corrupção no setor público; b) quando da colheita das informações buscar em pesquisas ou instituições que sejam confiáveis; c) na elaboração dos dados permitir uma margem de variação de pontos na escala, não apenas entre países, como dentro do próprio país; d) colher opiniões de especialistas no país analisado, ou pessoas que fazem negócios no país (grandes empresários). Na fase posterior, é feito uma coleta de 13 tipos de informações, dentre elas o nível de suborno, o uso de recursos públicos para ganhos privados, o nível de nepotismo, a capacidade do Estadonação conseguir criar medidas para que reforce a integridade e políticas de éticas contra a corrupção, a proteção de testemunhas e de delatores, dentre tantos outros fatores. O Índice de Percepção da Corrupção então padroniza as pontuações numa escala de $0-100$, onde 0 significa que a percepção da corrupção é a mais alta e números próximos de 100, encontram níveis de corrupção mais baixo. Feito essa etapa será calculado uma média entre países, e o índice será elaborado. Salientamos que essa é uma visão muito resumida do que de fato ocorre, ressaltamos novamente que questões técnicas mais aprofundadas a transparência internacional disponibiliza com um detalhamento maior em seu próprio site. Para mais informações acessar: https://www.transparency.org/cpi2018 
social, a redução é paulatina e morosa, quiçá inócua. Fernando Filgueiras (2011, p. 366) cita uma mudança de paradigma em solo nacional, apesar da corrupção ainda estar presente no cotidiano:

Pode-se dizer que, no Brasil depois de 1988, configurou-se uma política pública de controle e combate à corrupção. Se associada a princípios como responsabilidade fiscal e controle de gastos, percebe-se um avanço da gestão, apesar de a corrupção ser uma prática ainda comum e recorrente.

Dos dados expostos percebe-se que não há dificuldade em medir a corrupção de maneira genérica, a julgar pela riqueza de dados de várias pesquisas que apontam o quão perceptível a corrupção é aos olhos de todos, porém a dificuldade reside em ponto de importância ímpar, qual seja medir o tamanho e a necessidade de uma reforma para mitigar ou extinguir a corrupção (JOHNSTON, 2005). Para ficar ainda mais claro, é notório que o Brasil encontra-se em uma má posição no Índice de Percepção de Corrupção e que a reforma necessária seria de uma proporção gigantesca, porém como seria operacionalizada tal reforma? Apenas dispositivos legais seriam suficientes? Caso não fossem, quais outras medidas seriam necessárias? Em um mundo ideal, os números da corrupção seriam detalhados com extrema minúcia, o que tornaria seu combate potencialmente mais eficaz. A precisão em empregar a cura para este mal, em tal cenário utópico, perfeito, similar às instituições da ilha de Thomas More, seria mais efetiva, porém, em razão de faltar uma vítima imediata, dado que os atos de corrupção geralmente têm como destinatários toda a sociedade de forma indiscriminada, dificulta verdadeiramente seu relato de maneira plena.

Zani Andrade Brei (1996, p. 106) traz observação pertinente sobre a relação da corrupção dos países desenvolvidos e em desenvolvimento:

O problema não diz respeito unicamente aos países subdesenvolvidos. Não existe monopólio americano ou europeu da moral. As causas é que são diferentes e, portanto, são também provavelmente diferentes os efeitos em países desenvolvidos e subdesenvolvidos. Nos últimos, constata-se muitas vezes a ausência de um forte sentido de nacionalidade, grande desigualdade na distribuição da renda, o acesso à riqueza feito principalmente por meio de cargos políticos e a baixa legitimidade das instituições de governo. Daí os custos de atos corruptos se manifestarem por certo nível de decomposição do Estado e da sociedade civil, pela instabilidade gerada pela maior destruição da legitimidade das estruturas políticas, pelo desperdício de recursos em decorrência da evasão de riquezas para outros países, e até mesmo pela alienação de bons servidores civis, redução de seus esforços ou sua retirada do país.

Problema que também paira sobre a questão da corrupção é a subjetividade de seu conteúdo e como ela é encarada em diferentes comunidades, alterando-se consequentemente ideias ligadas ao que é correto ou errado; enquanto há aqueles que podem considerar determinado ato como corrupto, outros podem considerá-lo como uma prática corriqueira ou mesmo honesta 
(VORSTER, 2013).

Não é apenas a subjetividade que afeta a ética, a própria dinamicidade da vida (liquidez), modifica a noção do que é probo, pois os antigos valores já não se adequam à realidade atual, Bauman (2000, p. 94) a esse respeito assevera:

É difícil conceber uma cultura indiferente à eternidade e que evita a durabilidade. Também é difícil conceber a moralidade indiferente às conseqüências das ações humanas e que evita a responsabilidade pelos efeitos que essas ações podem ter sobre outros. $\mathrm{O}$ advento da instantaneidade conduz a cultura e a ética humanas a um território não mapeado e inexplorado, onde a maioria dos hábitos aprendidos para lidar com os afazeres da vida perdeu sua utilidade e sentido.

Para explanarmos de forma clara a subjetividade do probo e do incorreto, nos utilizamos dos pensamentos de Sérgio Buarque de Holanda (1995, p. 141-142) que coloriu a expressão homem cordial. Para entender um pouco sobre a corrupção no Brasil, faz-se necessário entender suas palavras, assim é possível compreendermos um pouco mais a relação que o brasileiro tem com o Estado e com as próprias leis:

O Estado não é uma ampliação do círculo familiar e, ainda menos, uma integração de certos agrupamentos, de certas vontades particularistas, de que a família é o melhor exemplo [...] O conflito entre Antígona e Creonte é de todas as épocas e preserva-se sua veemência ainda em nossos dias. Em todas as culturas o processo pelo qual a lei geral suplanta a lei particular faz-se acompanhar de crises mais ou menos graves e prolongadas, que podem afetar profundamente a estrutura da sociedade.

Em razão exatamente dessa não diferenciação entre privado e público (ou trazendo à expressão pública um quê de intimidade) que é feita até hoje no Brasil, não raro, "a escolha dos homens que irão exercer funções públicas faz-se de acordo com a confiança pessoal que mereçam os candidatos, e muito menos de acordo com as suas capacidades próprias" (HOLANDA, 1995, p. 146). Este desprezo por uma disciplina social, marcado pela cordialidade que se constitui verdadeiro óbice a uma sujeição impessoal por parte do Estado é a marca do homem cordial.

Ou seja, através dessa familiarização ou confusão entre privado e público, as escolhas governamentais de pequeno porte ou de grande calibre são feitas levando-se em conta outros critérios, que não o da competência, da honestidade, da legalidade, da moralidade. Tais virtudes são postas de lado, e o "jeitinho brasileiro" torna-se institucionalizado. Deturpa-se a intenção do legislador não de maneira expressa, mas com aquela sinuosidade, com aquele traquejo, tão típico do povo que aqui vive. Exemplo atual da "cordialidade brasileira" é a insistência inquebrantável do presidente Michel Temer em nomear Cristiane Brasil ao posto de Ministra do Trabalho (URIBE; CARVALHO, 2018); conquanto não haja verdadeiro impedimento para assumir o cargo de Ministra do Trabalho por ter dívidas trabalhistas, mostra-se como desarrazoada a nomeação exatamente por colocar em um cargo de chefia quem exatamente descumpre as normas da pasta que deveria 
defender. Nesse sentido, a interpretação do que é corrupção ou não pode variar de povo para povo.

Logo, o que parece tão absurdo para determinado país pode ser algo completamente normal e corriqueiro em outro. Tais costumes "subjetivados" podem e geralmente são adotados por empresas nacionais públicas e privadas. Como assim? Embora seja proibida expressamente pela legislação nacional a compra de um agente público, ou o gesto de agraciá-lo com presentes de forma que o torne "simpático" a determinada causa, tais atos são banalizados a um nível que chega a ser incomum nunca ter ouvido, presenciado ou lido nos meios de comunicação fatos semelhantes. Caso de grande repercussão e relevância foi a compra de um anel para a esposa do então Governador do Rio de Janeiro Sérgio Cabral, que, segundo o empreiteiro Fernando Cavendish relatou, ocorreu da seguinte forma, de acordo com sua versão: Sergio Cabral levou o empresário a uma joalheria e disse "Estou presenteando a minha esposa e gostaria que você pagasse", a joia em questão, tratava-se de um diamante de quatro quilates, avaliado em 220 mil euros, todavia, tal presente ficaria condicionado a um favor mútuo por parte do agente público. Com efeito, meses depois a empresa de Fernando Cavendish entrou no consórcio do Maracanã. $\mathrm{O}$ mais interessante, porém, são as palavras do empresário: "Deixei claro que não era um presente. Acabou sendo um anel de compromisso.” (O ‘ANEL..., 2017).

Retiramos o fragmento da tradução do livro Espírito das Leis, que continua tão atual como nunca, embora seus escritos datem do século XVIII. A virtude (probidade, honestidade) sempre foi algo indispensável para os governos de todas as épocas:

Os políticos gregos que viviam no governo popular não reconheciam outra força que os pudesse sustentar a não ser a da virtude. Os de hoje não nos falam senão em manufaturas, em comércio, em finanças, em riquezas e mesmo em luxo. Quando essa virtude desaparece, a ambição entra nos corações que a podem receber, e a avareza penetra em todos eles. Os desejos mudam de objeto; aquilo que antes se amava não mais se ama; o indivíduo era livre, vivendo de acordo com as leis; hoje cada qual quer ser livre, trabalhando contra elas; cada cidadão é tal qual um escravo fugido da casa do seu senhor, aquilo que outrora era máxima chamase hoje rigor; o que era regra, chama-se opressão; o que era atenção chama-se temor. A frugalidade é aí a avareza, e não o desejo de possuir. Outrora, o bem dos particulares formava o tesouro público; mas nesse tempo, o tesouro público tornase o patrimônio dos particulares. A república é um despojo, e a sua força não é mais do que o poder de alguns cidadãos e a licença de todos (MONTESQUIEU, 1990, p. 53).

A corrupção é tão habitual entre agentes públicos (entenda-se na acepção mais ampla da palavra) e empresários no Brasil que falarmos de desvio de dinheiro para fins vedados, limitado apenas à criatividade do corruptor ativo e passivo, torna-se um verdadeiro clichê.

Gregório de Matos (ou boca do inferno para aqueles que o alcunharam, tamanha audácia e perspicácia de sua língua) em seu poema "define a sua cidade", traz interessantes versos que são tão atuais como se tivessem sido escritos no século 21 , com exceção de que em vez de falarmos apenas da Bahia, o poema seria melhor aplicado ao Brasil como um todo: 
De dous [sic passim] ff se compõe esta cidade a meu ver, um furtar, outro foder. Recopilou-se o direito, e quem o recopilou com dous ff o explicou por estar feito e bem feito: por bem digesto e colheito, só com dous ff o expõe, e assim quem os olhos põe no trato, que aqui se encerra, há de dizer que esta terra De dous ff se compõe. Se de dous ff composta está a nossa Bahia, errada a ortografia a grande dano está posta: eu quero fazer aposta, e quero um tostão perder, que isso a há de perverter, se o furtar e o foder bem não são os ff que tem Esta cidade a meu ver. Provo a conjetura já prontamente com um brinco: Bahia tem letras cinco que são BAHIA, logo ninguém me dirá que dous ff chega a ter pois nenhum contém sequer, salvo se em boa verdade são os ff da cidade um furtar, outro foder (MATOS, 1996, p. 4).

Em um contexto globalizado, para os mercados se interligarem ao menos de forma harmônica, alguns "costumes impróprios" devem ser mitigados e combatidos, sob pena de não se garantir uma concorrência salutar, neste contexto, as ideias de compliance começam a florescer, cujo tópico será tecido nas linhas abaixo.

\section{COMPLIANCE NO CONTEXTO NACIONAL}

Pelos dados expostos é possível inferir que não é apenas coincidência, quanto mais deficiente é o Estado, maior é a corrupção.

Porém, há mecanismos legais que são desenvolvidos, principalmente em uma escala internacional, para mitigar atos corruptivos. Um dos instrumentos utilizados são as práticas de compliance que acabam por influenciar inclusive a legislação nacional de determinado país.

O vocábulo e a filosofia por trás das ideias de compliance não são recentes em território nacional como poderia se pensar em um primeiro momento. O Banco Central (Bacen), por meio da resolução ${ }^{\circ} 2.554$ de 1998 (inspirada em regras advindas do Comitê da Basiléia para Supervisão Bancária, da Europa de 1975 e da Securities and Exchange Commission, oriunda dos Estados Unidos), trazia em seu texto elementos como o controle interno, o incentivo a uma cultura organizacional ética, e outras ideias para balizar as instituições financeiras (BANCO CENTRAL DO BRASIL, 1998). A possibilidade de trazer benefícios diretos para quem adota as tais políticas de combate à corrupção foi a novidade (MARTINEZ, 2016), prerrogativa advinda do texto da lei 12.846 de 2013 conhecida como lei anticorrupção (nascida de compromissos internacionais que o Brasil assumiu, em especial a Convenção sobre o Combate da Corrupção de Funcionários Públicos Estrangeiros em transações comerciais internacionais, da OCDE, consubstanciado pelo Decreto 3.678 de 2000) (BRASIL, 2000).

Nas palavras de Leopoldo Pagotto (2013, p. 21):

Até recentemente, os Estados não precisavam se preocupar com o que os outros Estados faziam dentro de seus territórios - somente em raras ocasiões, havia um elemento extraterritorial envolvido. No entanto, o advento da globalização 
e da interdependência econômica integrou os países como nunca e forçou os diferentes Estados a observar os problemas de seus pares, tanto quanto seus próprios. Em realidade, passou-se a prestar mais atenção ao fato de que certas políticas públicas adotadas por um Estado podem impactar diretamente sobre as de outro Estado. Essa visão se torna mais impressionante quando o tema é a corrupção. Fazer vistas grossas ao que se passa fora de suas fronteiras, atitude imbuída do mais puro espírito hobbesiano, não é mais possível. Exige-se uma postura proativa face à corrupção ocorrida no exterior e seus impactos sobre o território nacional. Afinal, a inação pode trazer efeitos deletérios àqueles Estados que forem passivos.

É nesse contexto que surge o compliance. Mas qual seria o significado de tal expressão? A palavra é oriunda do verbo to comply, que em tradução direta seria cumprir, contextualizando o significado para o mundo empresarial e do direito, seria o mesmo que dizer: cumprir regras internas, externas (leis e outros dispositivos semelhantes de caráter nacional e internacional), prevenindo, detectando ou reprimindo qualquer conduta anormal, ou desvio proposital das práticas consolidadas de determinado negócio empresarial, evitando-se, assim, atos corruptos, inclusive por meio de códigos comportamentais internos da própria empresa. A essência do compliance pode ser conceituada da seguinte forma:

A maioria das empresas precisa, em algum momento, se relacionar de forma direta ou indireta com autoridades ou entidades governamentais. Em determinados setores, o grau de dependência para com entidades desta natureza é tão grande que se faz necessário implementar um programa de anticorrupção eficiente, o qual é fundamental para mitigar riscos reputacionais e/ou garantir a conformidade com a legislação e regulamentações (CLAYTON, 2013, p. 149).

A importância do termo ganha destaque, principalmente, em um cenário globalizado, onde qualquer desequilíbrio tem efeitos indesejados na economia de todo o mundo. Uma empresa que paga propina para "incentivar" uma agilidade maior de determinado agente público, ou mesmo para que o citado agente não "enxergue" determinados vícios na empresa, pode alterar seu preço, tanto para mais quanto para menos, vez que conseguirá uma vantagem injusta frente à concorrência. A excessiva regulação da exploração de recursos naturais, por exemplo, é particularmente benéfica para quem pratica a corrupção, visto que, ao descumprirem-se as normas, grandes lucros serão auferidos em virtude da burocracia excessiva que permeia o negócio; tempo é perdido, e tempo é dinheiro, sendo a corrupção um custo a ser contabilizado ao calcular futuros lucros.

O pagamento de tributos também possibilita a mesma abertura. Excessiva carga tributária pode gerar um efeito adverso nas atividades econômicas. É mais interessante aos indivíduos que devem mais tributos pagar propinas (NAWAZ, 2010) para que o peso da carga tributária seja menor, dado que o agente arrecadante cobrará com menor ênfase, um menor entusiasmo na cobrança será empregado. O que, por conseguinte, reduz o custo de um bem ou serviço/vendido.

Sobre a obrigatoriedade da adoção de programas de compliance por intermédio de medidas 
efetivas, o tema ainda necessita de um maior cuidado em seu tratamento, um esmero singular de quem deseja elevar a um patamar de importância global a prática de gestos probos no Brasil, por conta de não ser obrigatório para todas as pessoas jurídicas. Todavia, não é porque a legislação não obriga de maneira cabal sua adoção, que a opção de adotar as práticas de compliance deixe de se tornar interessante. $\mathrm{O}$ art. $7^{\circ}$, VIII da lei anticorrupção traz um incentivo que deve ser levado em conta por aquele que deseja uma melhor atuação empresarial:

Art. $7^{\circ}$ Serão levados em consideração na aplicação das sanções:

VIII - a existência de mecanismos e procedimentos internos de integridade, auditoria e incentivo à denúncia de irregularidades e a aplicação efetiva de códigos de ética e de conduta no âmbito da pessoa jurídica (BRASIL, 2013, grifo nosso).

O legislador deixa claro que, existindo programas de compliance, as sanções poderão ser eventualmente reduzidas, o que de per si corrobora com uma nova ótica, novos pensamentos no sentido de reduzir a corrupção no âmbito das pessoas jurídicas. A crítica que fazemos ao dispositivo, porém, reside na questão temporal, pois a redação textual fala que será levada em conta a "existência de mecanismos", todavia não deixa claro se deve existir previamente a prática dos ilícitos previstos na própria lei anticorrupção ou se podem ser criados posteriormente, o que pode comprometer o raciocínio preventivo das medidas de compliance.

Denise Bittencourt Friedrich e Rogério Leal (2015, p. 82) pontuam no mesmo sentido, a respeito da falta de delimitação do assunto:

Referente ao sistema de integridade, a Lei Anticorrupção perdeu a oportunidade de regular melhor os instrumentos de compliance, uma vez que apenas trouxe no artigo $7^{\circ}$, inciso VIII que a existência de mecanismos e procedimentos internos de integridade, auditorias e denúncias de irregularidades pode atenuar as sanções administrativas. Deveria ter descrito estas medidas levando em conta que não basta alegar a existência de um programa de compliance, se este for insuficiente ou apenas existir formalmente.

A crítica à redação não é desarrazoada, primeiramente pelo tema ser tratado de maneira original nos escritos da lei anticorrupção, que de per si, mostra-se como verdora, em um mar de leis antigas; em segundo lugar, a hermenêutica busca o real sentido das letras da lei evitando, inclusive, controvérsias que podem ser suscitadas no abarrotado judiciário. A esse respeito, extraímos segmento que julgamos relevante:

A interpretação é, assim, por efeito conclusivo, a crítica interna da lei, que lhe permite uma verdadeira "transparência", com o consequente conhecimento científico da norma jurídica, em todas as suas dimensões, em pleno e necessário complemento ao próprio estudo da norma jurídica em termos gerais. Não representa nenhum exagero, sob a ótica anteriormente exposta, afirmarmos que 
o estudo e o conhecimento da hermenêutica revestem-se de uma importância verdadeiramente capital no contexto das Ciências Jurídicas, considerando ser seu objetivo específico, exatamente, a indispensável sistematização dos processos aplicáveis, objetivando, em última análise, determinar o sentido final e o alcance específico das variadas expressões do Direito (FRIEDE, 2000, p. 134, grifo nosso).

A interpretação, tarefa hercúlea, imprescindível à análise da lei seja qual for, é verdadeira necessidade que não pode ser deixada de lado, principalmente no caso de institutos que são importados de realidades diferentes da nacional. O compliance, por não ser oriundo da legislação brasileira, não poderia escapar de tal instrumento.

Ainda a respeito da tarefa interpretativa, assinalamos passagem de Bobbio (1995 p. 213) que traduz em seus dizeres a magnitude da empreitada:

A interpretação é uma atividade muito complexa que pode ser concebida de diversos modos. Baseia-se na relação entre dois termos, o signo e o significado do próprio signo, e assim, assume sombreamentos diversos, segundo os quais tende a gravitar para um ou para outro desses dois pólos: a interpretação pode ser ligada principalmente ao signo enquanto tal e tender a fazê-lo prevalecer sobre a coisa significada; ou ainda pode ser mais sensível à coisa significada e tender a fazê-la prevalecer sobre o signo puro; fala-se neste sentido respectivamente de interpretação segundo a letra e de interpretação segundo o espírito (pense-se nas diversas escolas de interpretação bíblica). De um outro ponto de vista, fala-se de interpretação estática e de interpretação dinâmica, dependendo de a atividade do intérprete tender exclusivamente à reconstrução fiel do que pretendia significar o autor dos signos, objeto da interpretação, ou vice-versa, tender ao enriquecimento do significado dos signos interpretados, para adequá-lo às exigências das variadas circunstâncias históricos-sociais - pense-se nos diversos modos em que pode ser interpretado um trecho musical.

Se entendermos que a necessidade da adoção de medidas de compliance deve necessariamente ser prévia aos atos corruptos elencados na lei anticorrupção, a legislação adotará um sentido de efetivo combate à corrupção, em nosso entender. No entanto, se a interpretação permitir conceber que o marco temporal, tanto prévio quanto posterior aos atos praticados seja irrelevante, podemos beneficiar, com uma redução de até $2 / 3$ do valor da multa aplicada (conforme art. $16 \S 2^{\circ}$ ), uma pessoa jurídica que adotou tal manobra no último segundo (uma das penalizações para quem pratica os atos definidos na lei em análise).

A dita multa gira em torno de " $0,1 \%$ (um décimo por cento) a $20 \%$ (vinte por cento) do faturamento bruto do último exercício anterior ao da instauração do processo administrativo, excluídos os tributos, a qual nunca será inferior à vantagem auferida, quando for possível sua estimação" (art. 6 $6^{\circ}$ I). A penalidade em comento mostra-se como consequência severa para a pessoa jurídica, o que pode levá-la a evitar condutas que possam causar tamanho rombo em suas finanças, porém, quando existe uma lacuna textual que pode majorar uma redução da penalidade 
financeira, interpretações divergentes vão surgir, e até que seja pacificado o assunto pelo judiciário ou pelo próprio legislativo alterando seu texto, um quê de insegurança jurídica pairará sobre a situação.

Quanto à compulsoriedade da pessoa jurídica privada que não mantém nenhum vínculo público com a Administração Pública², percebe-se que não há definição no tópico obrigatoriedade do acolhimento de ideias de compliance, embora seja recomendado, posto que esta, em um cenário hipotético, poderia se beneficiar no contexto da lei anticorrupção. Por outro lado, a realidade é diversa quando falamos de empresas públicas, sociedades de economia mista e suas subsidiárias pertencentes a União, Estados, Distrito Federal e Municípios, pois a lei 13.303 de 2016 (apelidada de lei das estatais) prevê expressamente o seguinte:

Art. $9^{\circ}$ A empresa pública e a sociedade de economia mista adotarão regras de estruturas e práticas de gestão de riscos e controle interno que abranjam:[...] $\S 1^{\circ}$ Deverá ser elaborado e divulgado Código de Conduta e Integridade, que disponha sobre: I - princípios, valores e missão da empresa pública e da sociedade de economia mista, bem como orientações sobre a prevenção de conflito de interesses e vedação de atos de corrupção e fraude; II - instâncias internas responsáveis pela atualização e aplicação do Código de Conduta e Integridade; III - canal de denúncias que possibilite o recebimento de denúncias internas e externas relativas ao descumprimento do Código de Conduta e Integridade e das demais normas internas de ética e obrigacionais; IV - mecanismos de proteção que impeçam qualquer espécie de retaliação a pessoa que utilize o canal de denúncias; V - sanções aplicáveis em caso de violação às regras do Código de Conduta e Integridade; VI - previsão de periódico, no mínimo anual, sobre Código de Conduta e Integridade, a empregados e administradores, e sobre a política de gestão de riscos, a administradores (grifo nosso).

$\mathrm{O} \S 4^{\mathrm{o}}$, do artigo em estudo vai além afirmando o seguinte:

O estatuto social deverá prever, ainda, a possibilidade de que a área de compliance se reporte diretamente ao Conselho de Administração em situações em que se suspeite do envolvimento do diretor-presidente em irregularidades ou quando este se furtar à obrigação de adotar medidas necessárias em relação à situação a ele relatada.

O tenro diploma traz em sua composição excertos que demonstram uma irretorquível tendência, o combate à corrupção deve ser feito não apenas pelos particulares em seu âmbito

2 A expressão "pessoa jurídica privada que não mantém nenhum vínculo público com a Administração Pública”, embora pareça redundante, foi utilizada com o objetivo de separar as empresas privadas particulares das empresas estatais, que embora tenham natureza de pessoa jurídica de direito privado, mantêm características públicas como no caso da empresa pública onde todo o seu capital é público, e na sociedade de economia mista, onde a maioria do capital deve ser estatal. Ressalte-se que o vínculo com a Administração Pública permanece não apenas no tocante ao dinheiro, pois há uma derrogação mesmo que parcial do direito privado para normas do direito público; princípios do direito administrativo incidem sobre as empresas estatais (gênero), ainda que de forma mais atenuada, exemplo clássico é o seguinte: se houver destinação de dinheiro público para as empresas estatais para as folhas de pagamento, estas não poderão pagar salários maiores que o teto constitucional havendo limitação para tal (princípio da legalidade); vedação que jamais ocorreria com uma empresa privada. As empresas estatais estão próximas de um regime de direito misto/híbrido entre público e privado, pendendo por vezes para um lado, por vezes para o outro, dependendo da situação. 
interno, mas também pelo Estado, inclusive quando exerce funções que não lhe são próprias, como a atividade empresarial. Com efeito, o diploma não inova apenas na adoção obrigatória do compliance, seu texto reconhece um fato que anteriormente não era muito bem-vindo, ainda que de forma implícita, operou-se verdadeira metamorfose tão variada quanto a do caixeiro viajante Gregor Samsa quando transfigurou-se em barata (KAFKA, 2009), qual seja, a admissão de que entes da Administração Pública indireta podem praticar atos corruptos, não sendo apenas consideradas como "vítimas", portanto podem inclusive ser responsabilizadas.

$\mathrm{O}$ argumento de que a mudança de paradigma é radical demonstra-se como verdadeiro, pois todos os diplomas anteriores à lei anticorrupção e à lei das estatais, como a lei n 8.429 de 1992 (improbidade administrativa), lei no 8.666 de 1993 (licitações), o próprio Código Penal pátrio, com a tipificação dos crimes de corrupção ativa, tráfico de influência, corrupção passiva, associação criminosa colocavam já de antemão em um polo o Estado (Administração Direta e Indireta) como vítima de possíveis atos, podendo figurar como violador ou agente ativo do ato de corrupção a pessoa física, agente público ou mero particular (BRASIL, 1992, 1993). Todavia, aparentemente o legislador ignorou a possibilidade de pessoas jurídicas públicas e privadas poderem praticar atos corruptos, raciocínio que foi alterado no âmbito legislativo com a promulgação da lei anticorrupção e da lei das estatais.

De todo o exposto, podemos demonstrar algumas consequências: a adoção das práticas de compliance são obrigatórias somente para as empresas estatais. Tal afirmação, todavia, não pode ser extensível às empresas privadas em sua essência (não apenas em sua personalidade), que não são obrigadas atualmente no Brasil a adotar medidas de compliance, embora seja recomendável, caso a pessoa jurídica se envolva em práticas elencadas na lei anticorrupção, podendo inclusive se beneficiar de uma possível redução de multa prevista na própria lei. O elemento facultativo acaba por tornar-se explícito diante do regulamento da CGU que prevê em seu art. $1^{\text {o }}$ "O PróÉtica consiste na divulgação anual de uma relação de empresas que adotam voluntariamente medidas de integridade relacionadas à prevenção e ao combate à corrupção, e tem por objetivos." (CONTROLADORIA-GERAL DA UNIÃO, 2017, grifo nosso). Um dos objetivos do Pró-Ética é avaliar os critérios de boas práticas empresariais dos que se inscrevem anualmente; não obstante o foco da pesquisa ser outro, mas como o assunto é conexo, o único benefício de inscrever a empresa para a avaliação é que se esta conseguir passar pelos critérios ganhará um selo, porém como o $\S 2^{\circ}$ do art. $1^{\circ}$ narra "O Pró-Ética não é uma certificação e a aprovação para integrar a lista anual de Empresas Pró-Ética não gera à empresa quaisquer direitos, garantias ou privilégios em suas relações com o setor público.” (CONTROLADORIA-GERAL DA UNIÃO, 2017).

A legislação de forma direta cria uma distinção, há empresas que devem compulsoriamente adotar mecanismos de compliance enquanto outras a adoção fica a critério da empresa. Embora exista obrigatoriedade de as estatais observarem a lei 13.303, o Estadão trouxe notícia recente que surpreende:

Um ano e meio após a sanção da Lei das Estatais - criada para dar um caráter 
mais técnico às administrações de empresas públicas -, mais da metade ainda não cumpre a legislação. $O$ prazo para que elas ajustem seus estatutos às novas regras termina no dia 30 de julho. Das 147 estatais da União, 84 não aprovaram as mudanças que tentam barrar ingerência política. O levantamento, obtido pelo Estadão/Broadcast, foi feito pelo Ministério do Planejamento (TOMAZELLI, 2018).

Outro ponto destacado foi a respeito do critério temporal. As condutas de compliance devem ser adotadas previamente a prática dos atos elencados na lei anticorrupção, ou a qualquer tempo, haja vista que o legislador não especificou isto na redação? A questão é relevante, pois a adoção de práticas de compliance é um dos critérios para uma possível redução da pena financeira e, caso seja permitido a qualquer tempo, desvirtuaria o próprio significado da palavra que visa não só o combate posterior de atos maculados, mas também a prevenção. A lei nada fala a respeito, nem o regulamento da CGU que, diga-se de passagem, é quem deveria de forma completa traçar os parâmetros de avaliação do compliance (conforme parágrafo único do art. $7^{\circ}$ da lei anticorrupção), portanto temos aqui uma brecha a ser explorada na legislação nacional.

O autor Antonio Araldo Dal Pozzo (2014, p.106) vai além, em crítica mais acentuada a respeito da matéria ser restrita a regulamento do poder executivo, o que prejudica inclusive sua eficácia:

Tais regulamentos são atos administrativos que não podem inovar a ordem jurídica e, assim, não podem, a rigor, impor regras de criação de mecanismos ou critérios de avaliação para aplicação de sanções pelo Poder Judiciário, dado o princípio da legalidade (art. $5^{\circ}$, II da CF). Quer nos parecer, portanto, que sem lei formal o inciso será, irremediavelmente, letra morta ou, o que é bem pior, fonte de normas inconstitucionais. Melhor seria, talvez, deixar a avaliação do sistema de compliance a critério do Juiz de Direito

No tocante aos regulamentos, percebe-se a fragilidade de sua forma, pois, caso inove no ordenamento jurídico, beira a inconstitucionalidade e, caso nada faça, torna-se instrumento desnecessário, meramente decorativo.

Utilizamo-nos de um excerto de Ética a Nicômaco, livro de Aristóteles, (1991, p.35) com o fito de contextualizar o tema compliance:

Por conseguinte, as ações são chamadas justas e temperantes quando são tais como as que praticaria o homem justo ou temperante; mas não é temperante o homem que as pratica, e sim o que as pratica tal como o fazem os justos e temperantes. É acertado, pois, dizer que pela prática de atos justos se gera o homem justo, e pela prática de atos temperantes, o homem temperante; sem essa prática, ninguém teria sequer a possibilidade de tornar-se bom. Mas a maioria das pessoas não procede assim. Refugiam-se na teoria e pensam que estão sendo filósofos e se tornarão bons dessa maneira. Nisto se portam, de certo modo, como enfermos que escutassem atentamente os seus médicos, mas não fizessem nada do que estes thes prescrevessem. Assim como a saúde destes últimos não pode 
restabelecer-se com tal tratamento, a alma dos segundos não se tornará melhor com semelhante curso de filosofia.

Ora, aquele que segue pura e simplesmente as normas do compliance, não necessariamente previne a corrupção. A pessoa jurídica que tem boas práticas não é aquela que segue o ordenamento como lhe convém (aproveitando-se de brechas), ou para ganhar um benefício direto, mas sim as que praticam tal como se desejassem praticar suas atividades empresariais de forma honesta, ou seja, sem margem para condutas dúbias. Praticar apenas a formalidade legal, sem assimilar o espírito da ética, não diminuirá a corrupção, pelo contrário, trará apenas uma camuflagem, uma aparência de legalidade.

É sabido que a lei anticorrupção baseou sua estrutura em diplomas internacionais, dentre eles destacamos o Bribery Act do Reino Unido e o Foreign Corrupt Practices Act (FCPA) oriunda dos Estados Unidos, os quais utilizaremos para comparar com a legislação nacional no tocante à atenuação das penas, vejamos.

Ponto que foi insistentemente criticado por nós foi a lacuna da temporalidade das medidas de compliance, porém o Bribery Act, ao contrário da lei anticorrupção brasileira, não deixa dúvidas de quando deve ser acolhido pela pessoa jurídica. A seção 7 fala do cenário de uma possível falha na empresa em prevenir a corrupção; a defesa cabível para defendê-la reside em provar que houve a adoção de mecanismos preventivos para combater a corrupção de forma efetiva, sendo avaliadas as possibilidades das medidas terem sido efetivas ou não (UNIDET KINGDOM, 2010). Em outras palavras, não basta existir em teoria medidas que mitigam atos corruptos, pois será analisada no caso concreto a probabilidade do indivíduo se corromper ou não com as medidas adotadas, e como deve ter caráter preventivo, não há que se falar em adoção de ideias de compliance a posteriori.

O Foreign Corrupt Pratices Act trata do tema de forma diversa, pois não há atenuante para as pessoas jurídicas que praticam o compliance, ou alegação de uma defesa (UNITED STATES, 2012) como acontece no Bribery Act e na própria lei anticorrupção nacional (que pode ser levado em conta na atenuação da pena de multa). A discussão para criar um mecanismo de defesa da empresa por meio do compliance é antiga, sendo discutida desde 1986 (KOEHLER, 2012), porém, no corpo da FCPA, não há disposição com caráter semelhante. O que existe são guidelines (orientações, não lei propriamente dita) de como sentenciar as pessoas jurídicas, sendo um dos critérios de uma possível mitigação a existência de um programa de compliance que tenha caráter preventivo e repressivo no âmbito interno.

Logo, não seria possível uma adoção tardia do sistema para atenuar uma pena, situação que pode acontecer na lei anticorrupção nacional, ao menos do jeito que a redação se encontra atualmente.

Analisando a realidade americana, o avanço não é apenas no caráter preventivo e repressivo do compliance, as penalidades aplicadas pela $F C P A$ são baseadas, dentre outros fatores, em um termo chamado de Culpability Score (seria uma pontuação que avalia o quão culpada é a pessoa jurídica) para a aplicação das penas previstas na FCPA, tendo o compliance uma dedução 
de pontos totais da conta. As guidelines são divididas em diversas seções, mas, para melhor elucidação, passamos a discorrer a respeito.

A consistência e efetividade dos programas de ética e compliance, podem ser avaliados na análise de duas diretrizes previstas nas guidelines: se ao tempo em que a ofensa ocorreu, a pessoa jurídica tinha um programa efetivo de ética e compliance, observando-se critérios previstos no $\S 8 \mathrm{~B} 2.1^{3}$ :- subtraia-se 3 pontos. (UNITED STATES SENTENCING COMMISION, 2016); não se aplica a redução de pontos se, ao saber da ocorrência do ilícito a pessoa jurídica, sem motivo razoável, não reporta o evento às autoridades governamentais. (UNITED STATES SENTENCING COMMISION, 2016). Logo, o critério da temporalidade objeto de dúvida na atual lei anticorrupção não ocorre aqui, da simples análise das duas proposições acima enunciadas.

Não bastando tal fato, outro fragmento dentro das guidelines demonstra a seriedade do uso do compliance, pois traz parâmetros para demonstrar quando há uma presunção de que não existe um programa de compliance e ética efetivo no âmbito da pessoa jurídica. Por exemplo, se no âmbito desta não se constata um desvio comportamental fácil, não há que se falar em atenuação. Ou seja, se uma empresa de grande porte, em atenção a sua capacidade técnica, com corpo jurídico conceituado, não consegue prevenir infrações, certamente não há que se falar em efetividade de compliance, portanto não merece redução ou atenuação de futura pena no sistema americano. Alegar ignorância não afasta a responsabilidade, o fato de não saber de um possível ilícito não é escusa suficiente.

Ou seja, não basta apenas sustentar uma aparência de legalidade, uma honestidade dúbia, pois caso isso seja feito, o Culpability Score não sofrerá redução em sua pontuação.

Mona Clayton traz sua visão a respeito da utilização do compliance no Brasil, que embora seja incipiente demonstra certo avanço, porém as dificuldades ainda são visíveis em razão da mentalidade do empresariado:

A conscientização sobre a importância do compliance anticorrupção vem aumentando significativamentenos últimos anos. Isto se deve a uma série de fatores, dentre eles a crescente relevância global da economia brasileira e o aumento do investimento estrangeiro direto. No entanto, mesmo com a velocidade em que as mudanças estão acontecendo, ainda há um gap na cultura de compliance do país em comparação com mercados maduros. A adoção de políticas e procedimentos específicos anticorrupção ainda é pouco usual nas empresas brasileiras e a relativa falta de avaliação de riscos pode estar relacionada ao receio de serem encontradas surpresas. É comum que a ameaça de corrupção não esteja incluída na avaliação de riscos operacionais (CLAYTON, 2013, p. 152).

Há aqueles que afirmam que a previsão dos mecanismos de compliance de per si já é uma mudança de paradigma digna de elogio (LEAL; RITT, 2014), visto que seu caráter educativo demonstra uma intenção de combater uma situação de corrupção institucionalizada. O acolhimento

3 Para informações detalhadas a respeito vide: https://www.ussc.gov/guidelines/2015-guidelines-manual/2015-chapter-8 , seção $\S 8 \mathrm{~B} 2.1$ 
das ideias de compliance realmente não é de todo mal, porém sua efetividade é seriamente comprometida por pontos obscuros na lei anticorrupção.

Ao fazermos uma leitura dos anais de Cornelio Tácito traduzidos para o espanhol, buscamos desvendar o contexto em que a célebre frase foi proferida: Quanto mais corrupta é a república, mais abundantes são as leis. Percebe-se a similaridade entre a antiga Roma e o Brasil atual pelos seguintes motivos: Roma passava por um momento tempestuoso. Após a expulsão de Tarquínio, a população tomou diversas medidas contra as facções de senadores da época com o fito de proteger a liberdade e garantir a harmonia, foram instituídos os decênviros e, buscando bons exemplos que ocorriam fora de Roma, a lei das XII Tábuas foi criada (assim como hoje se buscam exemplos internacionais de leis, na época os exemplos eram obtidos nas redondezas); conforme novos infratores foram surgindo, novas leis iam sendo promulgadas, orientadas geralmente por razões distorcidas da ideia original, o que criou uma inflação legislativa (TÁCITO, 1979), é neste contexto que surge a expressão e o brocardo em latim "Corruptissima re publica plurimae leges". Recentemente com tantos escândalos, o Brasil também passa por transformações que abalam seu eixo, e a quantidade de leis existentes aqui, Roma jamais sonharia.

É certo que a lei anticorrupção trouxe avanços, todavia, a prática do compliance será disseminada? O compliance previsto na lei anticorrupção é efetivo? Somente o tempo dirá quais serão os resultados vindouros.

\section{CONCLUSÃO}

Conforme foi apontado durante todo o artigo, os mecanismos de compliance são necessários para um melhor desempenho empresarial, principalmente em um contexto globalizado. Porém, o quanto será efetivo, tendo-se em vista que tais políticas não são obrigatórias, salvo para as estatais (que ao menos até o início desse ano não vêm cumprindo com a legislação), compromete um efetivo combate a práticas desonestas. Seria viável para o pequeno empresário adotar as medidas de auditoria interna, incentivo à denúncia, contratar um corpo jurídico especializado para acompanhar todo este trâmite? Parece que o resultado, ao menos no aspecto financeiro não seria vantajoso. Ou seja, cria-se uma distinção que não há sentido em nosso entender, o compliance deveria ser obrigatório para todas as pessoas jurídicas e incentivado pelo Estado de forma gratuita para um verdadeiro combate à corrupção, situação que infelizmente não ocorre.

Por outro lado, é interessante a adoção das medidas de compliance de um ponto de vista racional e objetivo no âmbito das empresas de grande porte, que podem arcar com os custos da implementação de um programa complexo, que, a longo prazo, pode reverter em economia, pois uma pessoa jurídica que não se envolve em crimes de corrupção economiza com advogados para o potencial litígio, não desgasta sua marca e, por ser honesta em um país como o Brasil, encontra um verdadeiro diferencial que pode refletir em publicidade positiva, lucrando ativamente com sua honestidade, dentre tantos benefícios que poderiam ser elencados à exaustão.

Apesar disto, a crítica permanece ao instituto do compliance na lei anticorrupção que 
pode tornar-se apenas um verniz, uma maquiagem para simular atos legais, gerando benefícios a pessoas jurídicas que por vezes continuarão por anos a fio com as práticas corruptas. O instituto, embora não seja novo no Brasil, tem alguns problemas que podem causar verdadeiro incômodo.

Quando adotar as medidas de compliance? A pergunta é importante, pois uma das penalidades da lei anticorrupção é a multa no valor de $0,1 \%$ a $20 \%$ do faturamento bruto do último exercício anterior ao da instauração do processo administrativo, excluídos os tributos, a qual nunca será inferior à vantagem auferida, quando for possível sua estimação, e a adoção das medidas de compliance podem ser fator primordial, no caso concreto, de diminuição da citada pena em até 2/3. Ou seja, falamos de cifras volumosas que podem perder a severidade, visto que o legislador não disse a partir de quando o critério do compliance seria válido. A lei fala que será levada em conta a existência dos mecanismos de compliance, mas é omissa em dizer a informação mais importante, a partir de que momento a criação de instrumentos para combater e prevenir a corrupção serão relevantes para reduzir a pena? Se a pessoa jurídica adotar as medidas de compliance depois da prática dos atos elencados na lei anticorrupção merecerá redução da multa? Ou apenas quem se preveniu anteriormente e o ato acabou por ocorrer, merecerá o benefício? Não bastasse a brecha citada, o legislador permitiu que os parâmetros de avaliação das políticas de compliance fossem estabelecidos através de regulamento do Poder Executivo Federal.

O regulamento veio e nada disse a respeito do critério da temporalidade. Há aqueles, inclusive, que questionam a legitimidade do regulamento, afirmando que seria mais adequado a lei trazer os parâmetros objetivos, contemplando assim o princípio da legalidade, ou deixar para a avaliação do magistrado ao apreciar o caso concreto.

Como é notório, a lei anticorrupção baseou-se na legislação estrangeira com destaque para o Bribery Act e o Foreign Corrupt Pratices Act, porém a lei pátria inovou não definindo com firmeza quando o compliance deve ser adotado. O Bribery Act define que somente serão levados em conta como defesa os atos de compliance, se esses tiverem caráter preventivo, o que de per si demonstra uma inclinação para a necessidade da adoção das medidas antes do ilícito, já o Foreign Corrupt Pratices Act é mais severo, embora ainda hoje exista muita discussão, não admite alegação de defesa utilizando-se o critério de compliance.

Hoje a corrupção no Brasil é perceptível a todos, atingindo os mais diversos setores da sociedade sem distinção, propagando seus efeitos em proporções assustadoras. Seria o compliance previsto na lei anticorrupção um emplastro para medicar este câncer? Assim como a doença comentada, de cura possível, porém dificultosa, medicar a corrupção necessita mais do que medidas legislativas. O compliance será comparado com uma pílula para exemplos práticos: acaso prescreve-se um medicamento defeituoso, ou falho para um moribundo ou ainda sem comprovação de resultados? Antes de importar institutos, é necessário diligência para não reproduzir a forma e criar anomalias. Para a criação de um medicamento é necessário pesquisas, estudos, discussões, não a mera aceitação passiva e aplausos.

É certo que a fórmula do compliance seria modificada na realidade brasileira, porém como foi colocada torna-se instrumento de manobra processual para aqueles que saibam usá-la. 
A penalidade de multa pode perder por completo a sua eficácia, e a cultura empresarial não se alterará agravando-se a corrupção. Motivo pelo qual é sugerido algumas soluções para o problema desvendado na pesquisa: a alteração da lei anticorrupção para pacificar o critério da temporalidade, criando um marco de quando é válida a aplicação das políticas do compliance; ou a adoção do mesmo critério previsto na sistemática no Bribery Act; ou ainda a livre apreciação dos magistrados no caso concreto, criando-se diretrizes semelhantes às guidelines americanas.

Necessário, independentemente de quaisquer das medidas assinaladas, é um debate maduro, crítico e racional de qualquer instituto que seja, principalmente quando são oriundos de uma realidade estrangeira. A discussão e o combate à corrupção não devem ser feitos apenas quando escândalos brotam, a prevenção deve ser tal que extirpe o mal antes de nascer ou, sendo impossível, que suas consequências sejam as mais diminutas possíveis.

\section{REFERÊNCIAS}

ACKERMAN, Susan Rose. Corruption and government: causes, consequences and reform. United Kingdom: Cambridge university press, 1999.

ARISTÓTELES. Ética a Nicômaco. São Paulo: Nova Cultural, 1991.

BAUMAN, Zygmunt. Modernidade líquida. Rio de Janeiro: Zahar, 2000.

BANCO CENTRAL DO BRASIL. Resolução $\mathbf{n}^{\circ}$ 2.554, de 24 de setembro de 1998. Dispõe sobre a implantação e implementação de sistema de controles internos. Disponível em: http://www. bcb.gov.br/pre/normativos/res/1998/pdf/res_2554_v3_P.pdf. Acesso em: 1 jan. 2018.

BLANCHET, Luiz Alberto; AZOIA, Viviane Taís. A transparência na administração pública, o combate à corrupção e os impactos no desenvolvimento. Revista do Direito, Santa Cruz, v. 1, n. 51, p. 157-175, jan. 2017. Disponível em: https://online.unisc.br/seer/index.php/direito/article/ view/8897/6161. Acesso em: 1 jan. 2018.

BOBBIO, Norberto. O positivismo jurídico: lições de filosofia do direito. São Paulo: Ícone, 1995.

BRASIL. Decreto no 3.678 de 30 de novembro de 2000. Promulga a Convenção sobre o Combate da Corrupção de Funcionários Públicos Estrangeiros em Transações Comerciais Internacionais, concluída em Paris, em 17 de dezembro de 1997. Disponível em: http://www. planalto.gov.br/ccivil_03/decreto/d3678.htm. Acesso em: 1 jan. 2018.

BRASIL. Lei 8.429 de 2 de junho de 1992. Dispõe sobre as sanções aplicáveis aos agentes públicos nos casos de enriquecimento ilícito no exercício de mandato, cargo, emprego ou função na administração pública direta, indireta ou fundacional e dá outras providências. Disponível em: http://www.planalto.gov.br/ccivil_03/LEIS/L8429.htm. Acesso em: 1 jan. 2018.

BRASIL. Lei 8.666 de 21 de junho de 1993. Regulamenta o art. 37, inciso XXI, da Constituição Federal, institui normas para licitações e contratos da Administração Pública e dá outras providências. Disponível em: <http://www.planalto.gov.br/ccivil_03/Leis/L8666cons.htm>. Acesso em: 1 jan. 2018. 
BRASIL. Lei 12.846 de 1 de agosto de 2013. Dispõe sobre a responsabilização administrativa e civil de pessoas jurídicas pela prática de atos contra a administração pública, nacional ou estrangeira, e dá outras providências. Disponível em: http://www.planalto.gov.br/ccivil_03/_ ato2011-2014/2013/lei/112846.htm. Acesso em: 1 jan. 2018.

BREI, Zani Andrade. A corrupção: causas, consequências e soluções para o problema. Revista de Administração Pública, Rio de Janeiro, v. 30, n. 3, p.103-115, jun. 1996. Disponível em: http://bibliotecadigital.fgv.br/ojs/index.php/rap/article/viewFile/8088/6904. Acesso em: 1 jan. 2018.

UNIDET KINGDOM. Bribery ACT 2010. 2010. Disponível em: https://www.legislation.gov. uk/ukpga/2010/23/contents. Acesso em: 1 jan. 2018.

CLAYTON, Mona. Entendendo os desafios de compliance no Brasil: um olhar estrangeiro sobre a evolução do Compliance anticorrupção em um país emergente. In: DEL DEBBIO, Alessandra et al. Temas de anticorrupção \& compliance. Rio de Janeiro: Elsevier, 2013. p. 149-166.

CONTROLADORIA-GERAL DA UNIÃO - CGU. Regulamento Pró-etica. 2017. Disponível em: http://www.cgu.gov.br/assuntos/etica-e-integridade/empresa-pro-etica/arquivos/documentose-manuais/regulamento-2017.pdf. Acesso em: 1 jan. 2018.

DAL POZZO, Antonio Araldo. Lei anticorrupção: apontamentos sobre a lei nº 12.846/2013. Belo Horizonte: Fórum, 2014.

FILGUEIRAS, Fernando. Controle da corrupção e burocracia da linha de frente: regras, discricionariedade e reformas no Brasil. Dados - Revista de Ciências Sociais, Rio de Janeiro, v. 54, n.2, p. 349-387, abr. 2011. Disponível em: http://www.scielo.br/scielo.php?pid=S001152582011000200005\&script=sci_abstract\&tlng=es. Acesso em: 1 jan. 2018.

FRIEDE, Reis. Ciência do Direito, norma, interpretação e hermenêutica jurídica. Rio de Janeiro: Forense Universitária, 2000.

FRIEDRICH, Denise Bittencourt; LEAL, Rogerio Gesta. Aplicabilidade do dever de transparência e de informação da iniciativa privada frente o princípio da sustentabilidade ética nos contratos públicos. Revista Eurolatinoamericana de Derecho Administrativo, Santa Fé, v. 2, n. 2, p. 67-84, jul. 2015. Disponível em: https://bibliotecavirtual.unl.edu.ar/ojs/index.php/ Redoeda/article/download/5164/7867. Acesso em: 1 jan. 2018.

HOLANDA, Sérgio Buarque de. Raízes do Brasil. São Paulo: Companhia das letras, 1995.

JOHNSTON, Michael. Es posible medir la corrupcón ¿pero podemos medir la reforma?. Revista Mexicana de Sociologia, México, v. 67, n. 2, p. 357-377, abr. 2005. Disponível em: http://www. scielo.org.mx/scielo.php?script=sci_arttext\&pid=S0188-25032005000200004. Acesso em: 1 jan. 2018 .

KAFKA, Franz. A metamorfose. São Paulo: Hedra, 2009.

LEAL, Rogerio Gesta; RITT, Caroline Fockink. A previsão dos mecanismos e procedimentos internos de integridade: compliance corporativo na lei anticorrupção: sua importância considerado como uma mudança de paradigmas e educação empresarial. Revista Barbarói, Santa Cruz do Sul, ed. esp., n. 42, p. 46-63, jul. 2014. Disponível em: https://online.unisc.br/seer/ index.php/barbaroi/article/view/5544/3856. Acesso em: 1 jan. 2018. 
KOEHLER, Mike. Revisiting a foreign corrupt practices act compliance defense. Wiscosin Law Review, Wiscosin, v. 2012, n. 2, p. 610-660, jan. 2012. Disponível em: https://papers.ssrn.com/ sol3/papers.cfm?abstract_id=1982656. Acesso em: 1 jan. 2018.

MARTINEZ, André Almeida Rodrigues. Compliance no Brasil e suas origens. São Paulo: IBDEE, 2016. Disponível em: http://www.ibdee.org.br/compliance-no-brasil-e-suas-origens/. Acesso em: 1 jan. 2018.

MATOS, Gregório de. Seleção de obras poéticas. São Paulo: biblioteca Virtual do Estudante Brasileiro, c1996. Disponível em: http://www.dominiopublico.gov.br/download/texto/bv000119. pdf. Acesso em: 1 jan. 2018.

MONTESQUIEU, Charles de Secondat Baron de. O espírito das leis. São Paulo: Ediouro, 1990.

NAWAZ, Farzana. Exploring the relationships between corruption and tax revenue. Anticorruption Resource centre. 2010. Disponível em: https:/www.transparency.org/files/content/ corruptionqas/228_Exlporing_the_relationships_between_corruption_and_tax_revenue.pdf. Acesso em: 1 jan. 2018 .

O ‘ANEL de compromisso’ do empreiteiro com Sérgio Cabral. O Antagonista, 4 dez. 2017. Disponível em: https://www.oantagonista.com/brasil/o-anel-de-compromisso-empreiteiro-comsergio-cabral/. Acesso em: 1 jan. 2018.

PAGOTTO, Leopoldo. Esforços globais anticorrupção e seus reflexos no Brasil. In: DEL DEBBIO, Alessandra et al. (coord.). Temas de anticorrupção \& compliance. Rio de Janeiro: Elsevier, 2013. p. 21-48.

PORTO, Thiago Heitor da Fontoura; WERLE, Caroline Cristiane. A efetivação do princípio constitucional da publicidade dos atos administrativos como forma de coibição da corrupção pública mediante o controle social. Revista Barbarói, Santa Cruz do Sul, ed. Esp., n. 44, p. 137-154, jul. 2015. Disponível em: https://online.unisc.br/seer/index.php/barbaroi/article/ view/7441/4729. Acesso em: 1 jan. 2018.

ROCHA, Álvaro Filipe Oxley da; WERMUTH, Maiquel Ângelo Dezordi. O difícil processo de consolidação da cidadania plena no Brasil: notas sobre o patrimonialismo, o clientelismo, a corrupção e a pobreza política. Revista do Direito, Santa Cruz, n. 29, p. 146-165, jan. 2008. Disponível em: https://online.unisc.br/seer/index.php/direito/article/view/588/460. Acesso em: 1 jan. 2018.

TÁCITO, Cornelio. Anales Libros I-VI. Madrid: Gredos, 1979.

UNITED STATES. FCPA a resource guide to the u.s foreign corrupt practices act. US: Department of Justice, 2012. Disponível em: https:/www.justice.gov/sites/default/files/criminalfraud/legacy/2015/01/16/guide.pdf. Acesso em: 1 jan. 2018.

TOMAZELLI, Indiana. Mais da metade das empresas federais ainda não cumpre a Lei das Estatais. Estadão, São Paulo, 26 jan. 2018. Disponível em: http://economia.estadao.com. $\mathrm{br} /$ noticias/governanca,mais-da-metade-das-empresas-federais-ainda-nao-cumpre-a-lei-dasestatais,70002166035. Acesso em: 1 jan. 2018.

TRANSPARENCY INTERNATIONAL. Corruption Perceptions Index 2016. Jan. 2017 Disponível em: https://www.transparency.org/news/feature/corruption_perceptions_ 
index_2016\#table. Acesso em: 1 jan. 2018.

TRANSPARENCY INTERNATIONAL. Corruption Perceptions Index 2017. Feb. 2018.

Disponível em: https://www.transparency.org/news/feature/corruption_perceptions_index_2017. Acesso em: 1 jan. 2018.

UNITED STATES SENTENCING COMMISION. Sentencing of organizations. In: UNITED STATES SENTENCING COMMISION. Guidelines Manual 2016. US: United States Sentencing Commision, Nov. 2016. Chapter 8. Disponível em: https://www.ussc.gov/guidelines/2016guidelines-manual/2016-chapter-8\#NaN. Acesso em: 1 jan. 2018.

URIBE, Gustavo; CARVALHO, Daniel. Temer não desistiu de posse de Cristiane Brasil, diz Marun. Folha de São Paulo, são Paulo, 22 jan. 2018. Disponível em: http://www1.folha.uol. com.br/poder/2018/01/1952310-temer-nao-desistiu-de-posse-de-cristiane-brasil-diz-marun.shtml. Acesso em: 1 jan. 2018.

VORSTER, Schalk W. Fighting corruption - a philosophical approach. In die skriflig l in luce verbi, South Africa, v. 47, n. 1, p. 50-59, jul. 2013. Disponível em: https://indieskriflig.org.za/ index.php/skriflig/article/view/651. Acesso em: 1 jan. 2018.

YAZIGI, Alejandro Ferreiro. Dinero, política y transparencia: el imperativo democrático de combatir la corrupción. In: INTERNATIONAL ANTI-CORRUPTION CONFERENCE, 9., 1999, Durban. Disponível em: http://anterior.cdc.gob.cl/wp-content/uploads/2015/03/ AFERREIRO.pdf. Acesso em: 1 jan. 2018.

Como citar: CEREN, João Pedro; CARMO, Valter Moura do. Crítica ao compliance na lei brasileira de anticorrupção. Revista do Direito Público, Londrina, v. 14, n. 3, p. 87-109, dez. 2019. DOI: $10.5433 / 24157-108104-1.2019 v 14 n 3 p$. 87. ISSN: 1980-511X

Recebido em: 20/07/2018

Aprovado em: 01/04/2019 